\title{
Substorm observations by THEMIS D and ground-based observations by MAIN camera system in Apatity - a case study
}

\author{
Veneta Guineva ${ }^{1}$, Irina Despirak ${ }^{2}$, Rolf Werner ${ }^{1}$ \\ ${ }^{1}$ Space Research and Technology Institute - BAS, Stara Zagora, Bulgaria \\ ${ }^{2}$ Polar Geophysical Institute, Apatity, Murmansk region, Russia \\ E mail (﹎.guineva@yahoo.com).
}

Accepted: 14 May 2018

\begin{abstract}
In this work we studied the development of a substorm during the geomagnetic storm on 23 December 2014 using data of THEMIS D (THD) satellite, ground based magnetic field measurements and auroras observations by the Multiscale Aurora Imaging Network (MAIN) in Apatity. Solar wind and interplanetary magnetic field parameters were taken from the OMNI data base. THD was located at 7Re from 18:30 to 19:30 UT in the time interval 23-24 December 2014 and the projection of its orbit crossed Kola Peninsula in this time. A substorm was observed over Apatity from 19:19:50 UT on 24 December 2014. A comparative analysis between ground based and satellite data was carried out. High energy electrons $(1-10 \mathrm{keV})$ injections and reduction of the less energetic electrons flux $(\sim 100 \mathrm{eV})$ were observed during the substorm. Particles density reduction was found at the time about the auroras intensifications. Plasma fast flows were identified during the consecutive auroras intensifications. The time delay between the beginning of the different parameters disturbances registered by THD and the ground based observed ones is about $1.0 \div 1.5$ min.
\end{abstract}

(c) 2018 BBSCS RN SWS. All rights reserved

Keywords: solar wind, storms, substorms, auroras, THEMIS satellites measurements

\section{Introduction}

The problem of studying substorms during geomagnetic storms has long attracted the attention of researchers (e.g. Hsu and McPherron, 2000; Wu et al., 2004; Hoffman et al., 2010). Many researchers studied this problem using both satellite data and ground-based data (IMAGE magnetometers data, AL, AU indexes, data of auroras) (e.g. Tsurutani et al. 2004; Milan et al., 2008, 2009; Partamies et al., 2011; Despirak et al., 2009, 2011). It is known that as a result from storm investigations, the various phases of the storm were defined. Typically, initial, main and recovery phases of the storm are specified, while the storm recovery phase is divided into "near" and "late", into "rapid" and "recovery", and sometimes "structured recovery phase" was detected (e.g. Terada et al., 1998). It should be noted that when the magnetic storms are caused by several sources in the solar wind, coming consecutively one after another or partly overlapping, the storm recovery phase can be of very complicated form, and we will call such storms "storms with structured recovery phase" (Guineva et al., 2017a). One interesting event of such kind of storms, the storm on 23-26 December 2014, was considered in detail in our previous work (Guineva et al., 2017b), in which substorm auroras development in Apatity and its relationship with perturbed solar wind conditions were studied.

In the present work we will consider also a substorm on 24 December 2014, but we will compare Apatity`s ground-based observations and Themis satellite data. The case at 19:19:50 UT on 24 December 2014 is interesting, because Themis D was located at $\sim 7 \mathrm{Re}$ and from 18:30 to 19:30 UT the projection of its orbit crossed Kola Peninsula. It should be noted that there are very few cases of THEMIS satellites passing over the Kola Peninsula. One of these events, a case on 19 December 2014, was studied by Kozelova and Kozelov (2015). The authors have shown in particular that the high energetic particle injections and the sharp density decreases of less energetic particles occur near the substorm expansion phase onset.

In our work we used Kola Peninsula's data (measurements of auroras by the camera system MAIN, and Lovozero and Loparskaya magnetometers), IMAGE network and data from some other magnetometer stations at different longitudes and THEMIS D satellite data for comparative analysis of ground - based and satellite observations.

\section{Data}

Measurements from the Multiscale Aurora Imaging Network (MAIN) in Apatity during December 2014 have been used. This cameras observational system is described in detail by Kozelov et al. (2012). Apatity is located at auroral latitudes. Its geographic coordinates are: $67.58^{\circ} \mathrm{N}, 33.31^{\circ} \mathrm{E}$, and the corrected geomagnetic ones $-64.27^{\circ} \mathrm{N}, 112.10^{\circ} \mathrm{E}$ (all corrected geomagnetic coordinates (CGM) are given for the year 2014 and altitude $0 \mathrm{~km}$, they are calculated by the CGM transformation tool of OMNIWEB-NASA: https://omniweb.gsfc.nasa.gov/vitmo/cgm_vitmo.html). The cameras observational system comprises 4 auroral cameras with different fields of view providing simultaneous observations from spatially separated points. From each camera images keograms were built. In the keograms the North direction is up and the zero angle coincides with zenith. Auroras disturbances were taken from the data of the Apatity all-sky camera (images and keograms) and the Guppy F-044C (GC) camera with field of view $\sim 67^{\circ}$ (keograms).

Geomagnetic disturbances were verified by the ground-based data of IMAGE magnetometers network (using the meridional TAR-NAL and MEK-NOR chains (Tartu (TAR), CGMLat. $=54.72^{\circ} \mathrm{N}$ - Ny Ålesund (NAL), CGMLat. $=76.51^{\circ} \mathrm{N}$ ). The substorm longitudinal extent was verified by ground-based data of several magnetic stations at different longitudes, and latitudes in the range $68^{\circ} \div 73.5^{\circ} \mathrm{N}\left(64^{\circ}-70^{\circ} \mathrm{N}\right.$ CGMLat). Data 
from the following stations were used: Dixon Island (DIK) (CGMLat $=69.30^{\circ} \mathrm{N}$, CGMLon = $\left.156.29^{\circ} \mathrm{E}\right)$, Amderma (AMD) (CGMLat $=65.89^{\circ} \mathrm{N}, \mathrm{CGMLon}=$ $\left.136.55^{\circ} \mathrm{E}\right)$, Lovozero (LOZ) (CGMLat $=64.65^{\circ} \mathrm{N}, \mathrm{CGMLOn}$ $\left.=113.75^{\circ} \mathrm{E}\right)$, Ivalo (IVA) (CGMLat $=65.45^{\circ} \mathrm{N}, \mathrm{CGMLon}=$ $\left.107.68^{\circ} \mathrm{E}\right)$, Kevo (KEV) (CGMLat $=66.69^{\circ} \mathrm{N}, \mathrm{CGMLon}=$ $108.25^{\circ} \mathrm{E}$ ), Muonio (MUO) (CGMLat $=64.97^{\circ} \mathrm{N}$, CGMLon $\left.=104.20^{\circ} \mathrm{E}\right)$, Sørøya (SOR) (CGMLat $=67.58^{\circ} \mathrm{N}, \mathrm{CGMLon}$ $\left.=104.92^{\circ} \mathrm{E}\right)$.

Solar wind and interplanetary magnetic field parameters were taken from the 1-min sampled OMNI data base of the CDAWeb

(http://cdaweb.gsfc.nasa.gov/cgi-bin/eval2.cgi) and the catalog of large-scale solar wind phenomena (ftp://ftp.iki.rssi.ru/omni/)

The magnetospheric measurements were taken from THEMIS satellite data base

(http://themis.ssl.berkeley.edu/index.shtml). The THEMIS satellites were placed in highly elliptical orbits. The orbits apogee rotates slowly around the Earth and covers consecutively the dayside, dawnside, nightside and duskside of the magnetosphere. The examined case is in the so called Dusk Phase (Stage 28: from 17 October 2014 to 21 January 2015). The apogees of THD (P3), THE (P4) and THA (P5) are approximately 12 Re. The satellites are separated from 500 to $3000 \mathrm{~km}$. We used probe-generated ESA moments, FGM magnetic field data, ESA density and velocity measurements, and energy flux spectrograms for ions and electrons, SST energy flux spectrograms for ions and electrons from THD.
The projections of Themis D (P3) and Themis E (P4) orbits are shown in Figure 1. In addition, also the locations of Apatity (APT) and the enumerated above magnetic stations of the longitudinal chain are marked by a star. It is seen that Themis D orbit crossed Kola Peninsula on 24 December 2014 from about 18:30 to 19:30 UT. At that time, it was at about 7 Re from the Earth.

Below, comparative analysis of the case on 24 December 2014 by simultaneous observations of Themis D, auroras data from Apatity cameras and ground-based magnetometers is presented.

\section{Results}

\section{Overview of the interplanetary conditions}

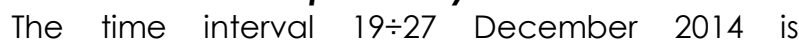
characterized by very complicated interplanetary conditions (Guineva et al., 2017a, 2017b). Several different solar wind structures (magnetic clouds - MC, high speed streams - HSS, some sharp fronts marking the boundaries between Sheath, MC, CIR and HSS) were observed, which overlapped. This highly disturbed interplanetary medium led to the development of two geomagnetic storms. The first storm, on 21 December 2014, can be considered as "classical". The second storm on 23 December 2014 is classified as a storm with structured recovery phase in which the SYM/H index undergoes sizable fluctuations of the range and higher than $0.5 * \mathrm{SYM} / \mathrm{H}_{\min }$ (Guineva et al., 2017a).

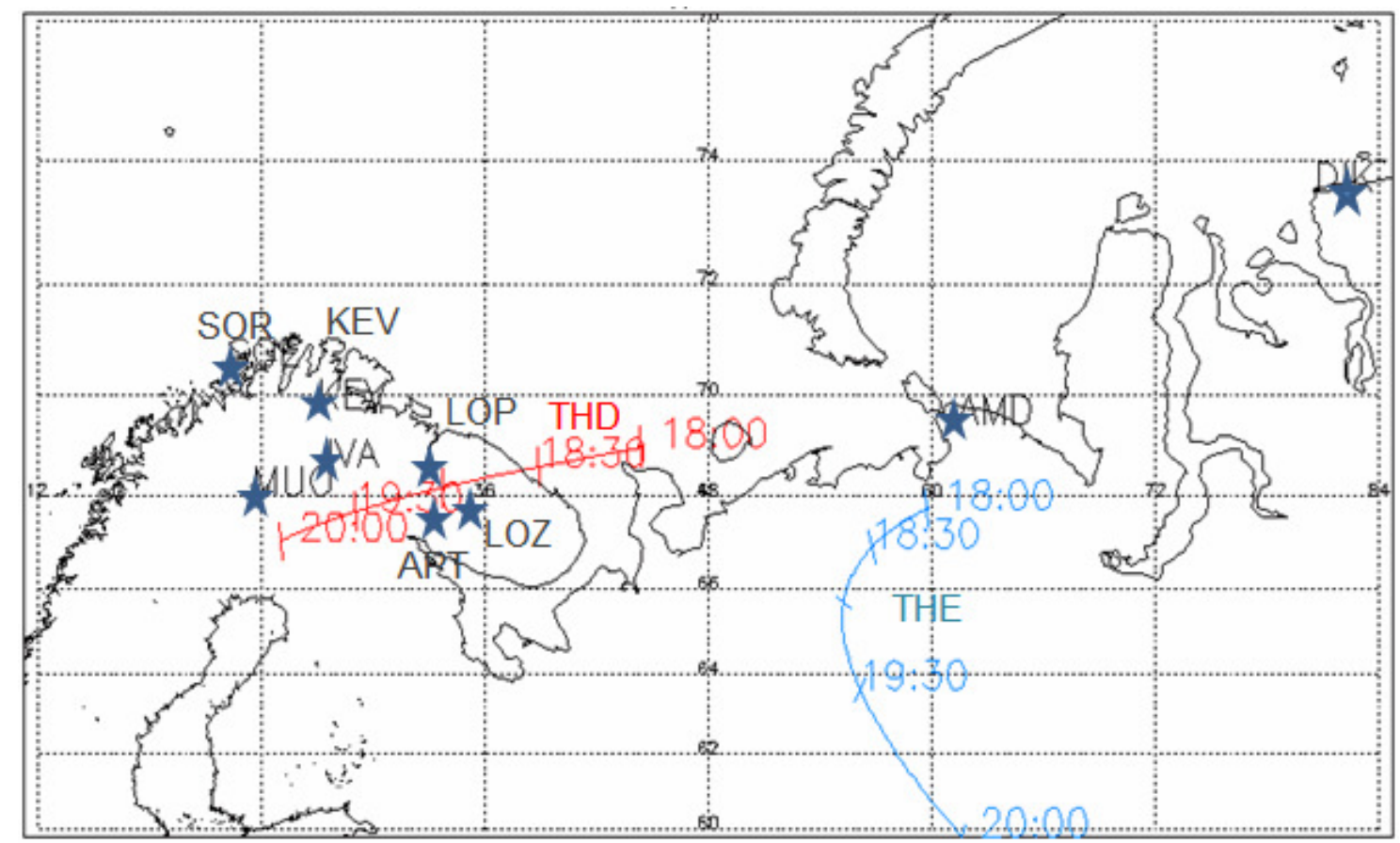

Figure 1. Magnetic lines projections of Themis D (red line) and Themis E (blue line) orbits on 24 December 2014 from 18 to 20 UT. From 18:30 to 19:30 UT THD passes above Kola Peninsula. The locations of Apatity (APT) and some magnetic stations at different longitudes are marked by blue stars (Lovozero (LOZ), Loparskaya (LOP), Muonio (MUO), Ivallo (IVA) and etc.) 

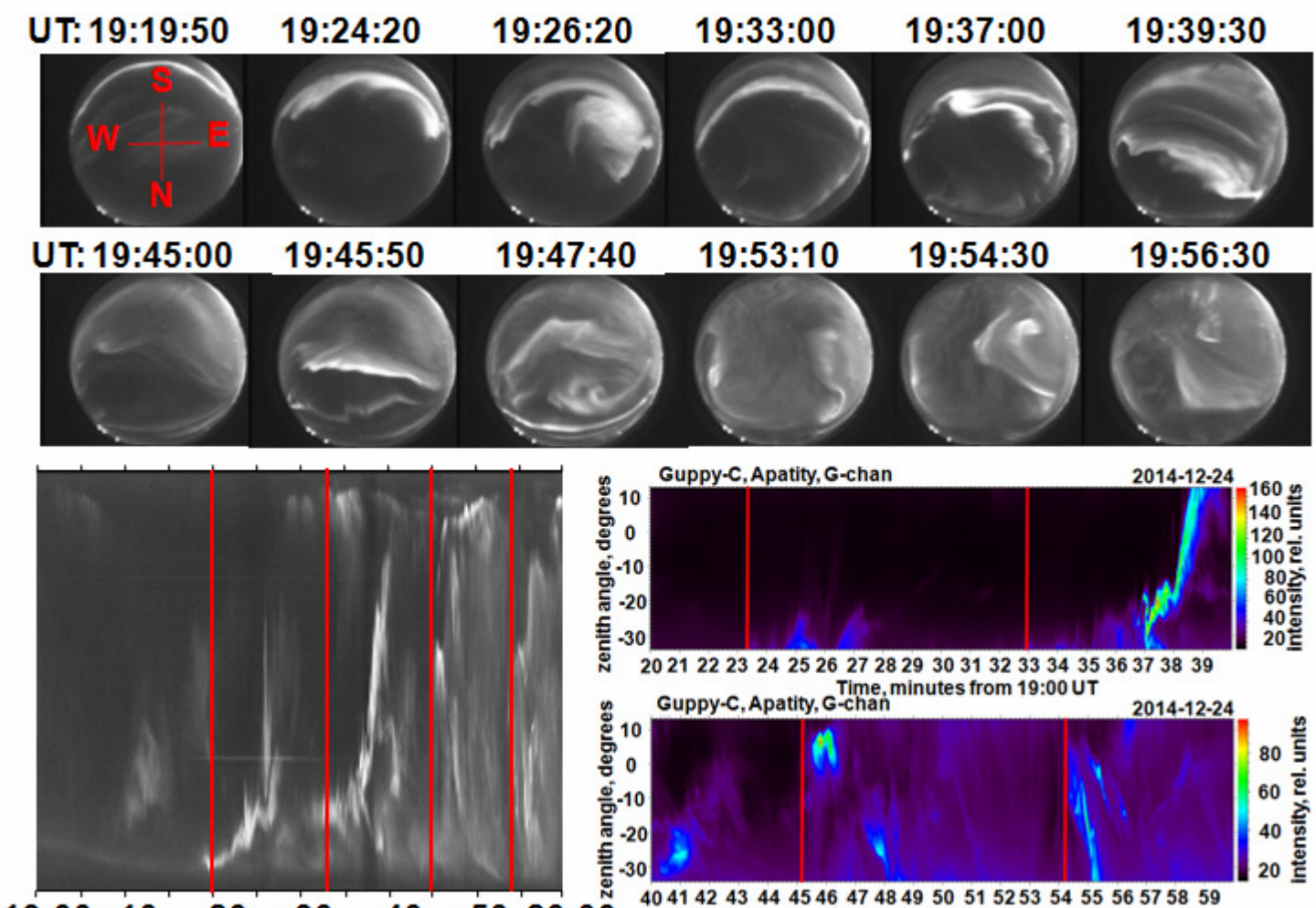

19:00: 10:20: : : :50 :20:00

Time, minutes from 19:00 UT

\section{December 2014, 19:00-20:00}

Figure 2. Development of the substorm at 19:19:50 UT on 24 December 2014 by chosen images of the all-sky camera (up) and the ASI keogram (bottom to the left) and GC keograms (bottom to the right). The world directions are indicated in the first image. The red vertical lines in the ASI and GC keograms mark the moments of the onset and three subsequent intensifications of the substorm.

\section{Substorm at 19:19:50 UT on 24 December 2014}

The substorm at 19:19:50 UT on 24 December 2014 occurred in the time interval, when the mapped orbit of THEMIS D on the North hemisphere crossed the Kola Peninsula. This substorm is presented as an example in the review of Guineva et al. (2017b). Here we examine the whole development of this substorm in more details with the purpose to compare the simultaneous ground based and satellite data for a longer time interval. The substorm originated during the structured recovery phase of the geomagnetic storm. The aurora dynamics during the substorm by the all-sky and GC cameras is presented in Figure 2. The substorm onset seen in auroras in Apatity was at 19:19:50 UT. The value of $\mathrm{SYM} / \mathrm{H}$ index at this moment was $-39 \mathrm{nT}$, the substorm onset was registered during a sharp decrease of the $S Y M / H$ index, related to a new geomagnetic disturbance, observed after the main phase of the geomagnetic storm (see more in Guineva et al., 2017a). The substorm auroras appeared in the South part of the field of view, thent moved to the North (the first three images in the upper row in Figure 2) and later covered the whole field of view. Up to 20:00 UT three consecutive intensifications of the substorm were observed at 19:33 UT, 19:45 UT and 19:53:10 UT. Each intensification is presented in Figure 2 by three chosen images of the beginning of the intensification (one image) and the following travel of auroras to North (two images). So the upper row in Figure 2 shows the substorm onset and the first intensification, and the lower row of images - the second and third intensifications. The cameras fields of view and the GC field of view and keogram boundaries regarding the all-sky keogram are described in detail by Guineva et al. (2017a). The all-sky keogram (the left bottom frame) spans one hour: from 19 to 20 UT. Two GC keograms are presented in the bottom right frame of Figure 2, everyone lasting $20 \mathrm{~min}$. The upper keogram spans from 19:20 UT to 19:40 UT, and the lower keogram covers the next $20 \mathrm{~min}$. from 19:40 UT to 20 UT. The substorm onset and the subsequent intensifications are marked by red vertical lines in the all-sky and GC keograms. The substorm onset was observed in the South part of the all-sky camera field of view, outside of the GC camera field of view, that is why the substorm auroras are seen lately in the GC keogram, when they entered the GC field of view during their movement to North. The substorm onset is seen faintly at 19:23:20 UT and stronger emissions were registered at 19:32:40 UT in the South part of the GC field of view. The first intensification after the substorm onset began also in the South part of the all-sky camera field of view, but to the North from the onset location, just near the GC field of view boundary. So the auroras are seen in both camera keograms at 19:33 UT. The second intensification began near the station zenith and is clearly seen in both cameras keograms at 19:45 UT. The third intensification was registered at 19:53:10 UT by allsky camera data and it is seen in the GC keogram from 19:54:10 UT. The maximal relative intensity in the GC camera field of view was 160 rel. units. 

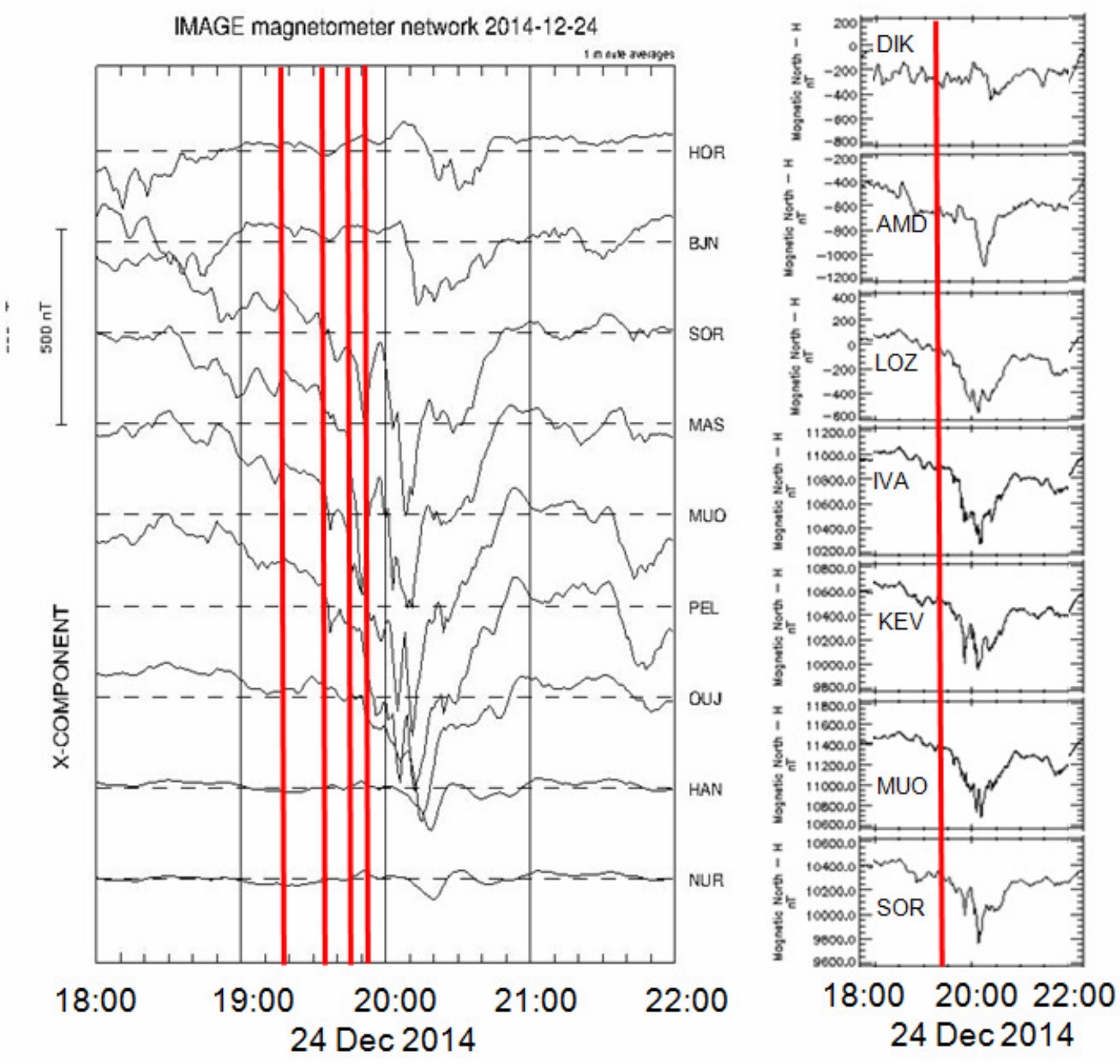

Figure 3. Bx component of the magnetic field by the IMAGE latitudinal chain NUR-NAL (the left panel) and the $\mathrm{H}$ component by some stations at different longitudes in the same latitudinal range (the right panel) from 18 to 22 UT on 24 December 2014. The red vertical lines in the left panel indicate the times of the substorm onset seen from Apatity and the subsequent intensifications by auroras data. The red line in the right panel marks the substorm onset by auroras data.

\section{Ground based magnetic field measurements on 24 December 2014}

In Figure 3 the magnetic field measurements of some stations of the latitudinal chain TAR-NAL (the left panel) and the stations at different longitudes, used as longitudinal chain (the right panel) from 18:00 to 22:00 UT on 24 December 2014 are shown. A long lasting magnetic disturbance in the evening was registered. The first magnetic disturbances began in the latitudinal range from about $63^{\circ} \mathrm{N}$ CGMLat (PEL) to $67^{\circ} \mathrm{N}$ CGMLat (SOR) and later expanded from NUR to HOR (the left panel of Figure 3). The longitudinal extent of the substorm was to the West of $\sim 35^{\circ}$ Lon $\left(113.75^{\circ}\right.$ CGMLOn) (LOZ). In the stations to the East from this longitude (DIK, AMD) no substorm was registered at this time. And at all the stations to the West of LOZ the substorm was observed (the right panel of Figure 3).

\section{Simultaneous all-sky and THEMIS D data on 24 December 2014}

The all-sky keogram from 19 to 20 UT on 24 December 2014 and some magnetosphere parameters measured at the same time by THEMIS D are presented in Figure 4. It is seen that the substorm onset happened nearly the time, when disturbances in all presented magnetospheric parameters began.

The beginning of the increased variations of IMF components at Themis $D$ (the three upper panels of THD data) was registered about 1-1.5 min. earlier than the substorm onset in Apatity. The disturbances were registered in the whole substorm duration, but they were higher again 1-1.5 min. before the three substorm intensifications.

Drops in the electron density (the fourth panel of THD data from up to down) are observed just after the substorm onset and the following intensifications.

Increase of the energetic electrons flux (1-10 keV) and reduction of the less energetic electrons flux $(\sim 100$ $\mathrm{eV}$ ) were observed all the time during the substorm (the fifth panel of THD data).

The electron flux and electron velocity components also show increased variations from about 1-1.5 min. before the substorm onset. 

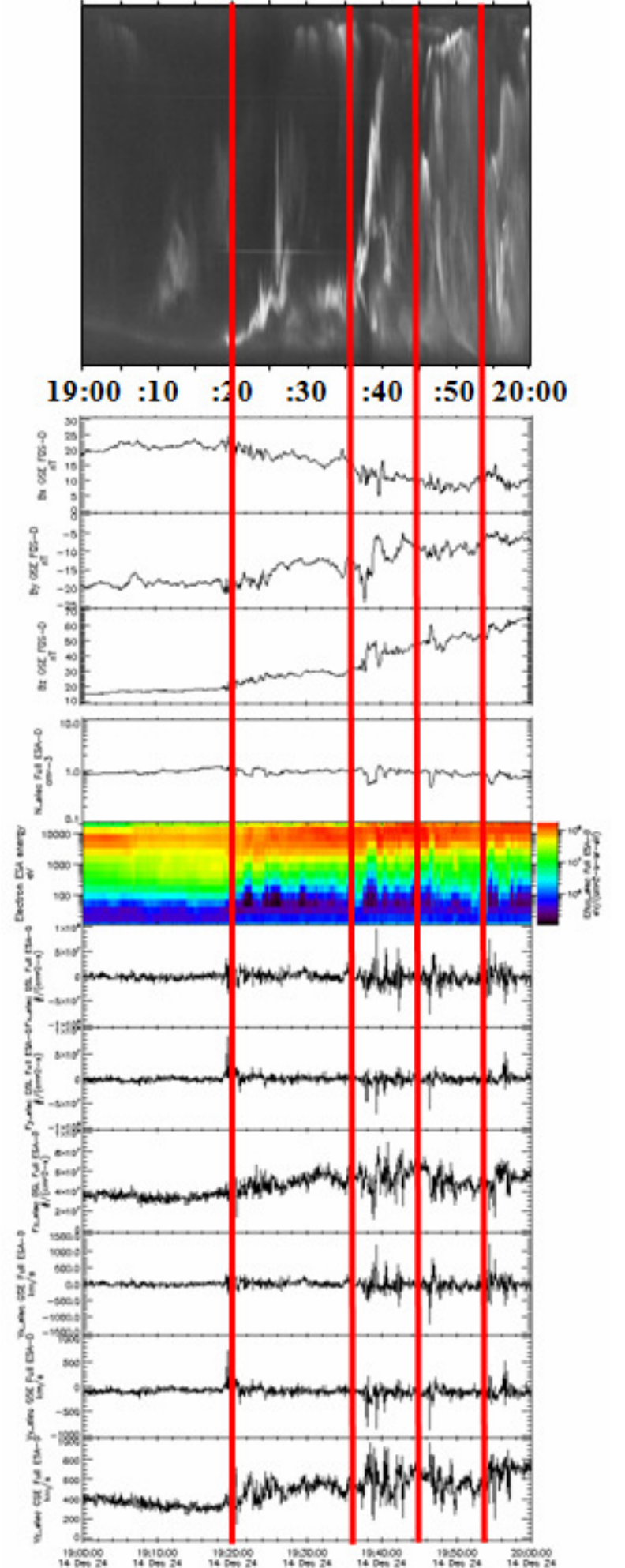

Figure 4. Substorm auroras (Apatity ASI keogram, at the top of the panels) and magnetic field and plasma Themis D data (below the ASI keogram) from 19 to 20 UT on 24 December 2014. From top to bottom: the $X, Y, Z$-components of the magnetic field by FIT, the electron density, the energy flux, the electron flux vector $\left(F_{X}, F_{Y}, F_{Z}\right)$ and the velocity vector $\left(V_{X}, V_{Y}, V_{Z}\right)$ of the electrons. The red vertical lines indicate the moments of the substorm onset and the three intensifications seen by ASI at Apatity.

\section{Discussion}

In this paper we present a case of substorm in the near magnetosphere (at $\sim 7$ Re from the Earth) dusk sector and the conjugate auroras activity at Apatity.

The substorm extent was verified by Earth magnetic field measured at different stations. A long lasting magnetic disturbance in the evening of 24 December 2014 was registered (Figure 3). The substorm development by magnetometers data and more precisely the boundary longitude was confirmed by the THEMIS D data: the increased variations of plasma parameters were registered from the moment when the mapped orbit crossed this longitude.

An increase of the high energy electrons and reduction of the lower energy electrons fluxes was observed during the substorm time (Figure 4). The same typical variations concerning a similar case of simultaneous substorm observations by all-sky camera in Apatity and THEMIS at 18:24 UT on 19 December 2014 were reported by Kozelova and Kozelov (2015).

A good coincidence with a delay of 1-1.5 minutes was found between the interplanetary magnetic field, the electron flux and the electron velocity components increased variations from one side, and the observed substorm onset and the three following substorm intensifications, from the other side.

The substorm onset and further substorm intensifications correspond to the registered drops in the electron density.

\section{Conclusions}

A comparative analysis between ground based and satellite data concerning the substorm on 24 December 2014 at 19:19:50 UT was carried out. We found that:

$>$ Increase of the energetic electrons flux (1-10 $\mathrm{keV})$ and reduction of the less energetic electrons flux $(\sim 100 \mathrm{eV})$ were observed during the substorm;

$>$ Particles density reduction was established at the time about the substorm onset and the beginnings of the subsequent intensifications;

$>$ Plasma fast flows were identified during the consecutive auroras intensifications;

$>$ The time delay between THD registered beginnings of the different parameters disturbances and the ground based observed ones is about $1.0 \div 1.5 \mathrm{~min}$.

\section{Acknowledgements}

We express our gratitude to Dr. B.V. Kozelov for the possibility of using the data of the observational cameras in Apatity, the construction of keograms and the useful discussions. WIND data used in this study were taken from $\mathrm{OMNI}$ through http://cdaweb.gsfc.nasa.gov/cdaweb/istp_public/.

We are grateful to J. N. King and N. Papatashvili, the heads of the experiments conducted with these instruments. THEMIS data were taken from the site http://themis.ssl.berkeley.edu/index.shtml. The paper was partly supported Program No 28 of the Presidium of the Russian Academy of Sciences (RAS). 


\section{References}

Despirak, I.V., Lubchich, A.A., Yahnin, A.G., Kozelov, B.V., Biernat, H.K.: 2009. Ann. Geophys. 27, 1951.

Despirak, I.V., Lubchich, A.A., Guineva, V.: 2011. J. Atmos. SolarTerr. Phys. 73, 1460.

Guineva, V., Despirak, I.V., Werner, R.: 2017a. J. Atmos. SolarTerr. Phys. doi: 10.1016/j.jastp.2017.09.014.

Guineva, V., Despirak, I., Kozelov, B.:2017b. Sun and Geosphere. ISSN 2367-8852. 12 (2), 111.

Hoffman, R.A., Gjerloev, J.W., Frank, L.A., Sigwarth, J.W.: 2010. Ann. Geophys. 28, 1183-1198. doi:10.5194/angeo-28-11832010.

Hsu, T.-S., McPherron, R.L.: 2000, Proc. of Fifth International Conference on Substorms, 16-20 May, 2000, St. Petersburg, Russia. Edited by A. Wilson. ISBN: 92-9092-772-0., 439.

Kozelov, B.V., Pilgaev, S.V., Borovkov, L.P., Yurov, V.E.: 2012, Geosci. Insrum. Method. Data Syst. 1, 1.

Kozelova, T.V., Kozelov, B.V.: 2015. "Physics of Auroral Phenomena”, Proc. XXXIII Annual Seminar, Apatity, 15.

Milan, S.E., Boakes, P.D., Hubert, B.: 2008. J. Geophys. Res. 113 A09215, doi:10.1029/2008JA013340.

Milan, S.E., Grocott, A., Forsyth, C., Imber, S.M., Boakes, P.D, Hubert, B.: 2009. Ann. Geophys. 27, 659

Partamies, N., Juusola, L., Tanskanen, E., Kauristie, K., Weygand, J.M., Ogawa, Y.: 2011. Ann. Geophys. 29, 2031.

Terada, N., lyemori, T., Nose, M., Nagai, T., Matsumoto, H., Goka, T.: 1998. Earth Planets Space. 50, 853.

Tsurutani, B.T., Gonzales, W.D., Guarnieri, F., Kamide, Y., Zhou, X., Arballo, J.K.: 2004, J. Atmos. Sol. Terr. Phys., 66, 167.

Wu, C.-C., Liou, K., Lepping, R.P., Meng, C.-I.: 2004. J. Atmos. Solar-Terr. Phys. 66, 125. 